\title{
CYBER WARFARE AND NATIONAL SECURITY IN NIGERIA
}

\section{KINGSLEY CHIGOZIE UDEGBUNAM ${ }^{1}$, CHARLES AKALE ${ }^{2}$ \& BLESSINGS EZINNE ESHILAMA ${ }^{3}$}

${ }^{I}$ Peace and Conflict Resolution Unit, School of General Studies, University of Nigeria, Nsukka, Enugu-Nigeria

${ }^{2}$ Research Fellow, Centre for Strategic Research and Studies, National Defence College Abuja-Nigeria

${ }^{3} \mathrm{PhD}$, Department of History and International Studies, University of Uyo, Uyo-Nigeria

\begin{abstract}
Nigeria is a theatre for many cybercriminal activities and attacks that have constantly threatened her national security. Many institutions, including financial and telecommunications, have continued to suffer huge monetary losses as a result of cyber war declared on the nation by certain criminal elements in the society. The vulnerability of cyberspace has allowed the invasion of Nigeria's cyber infrastructure and consequently impacting negatively on national security. The need to secure national cyberspace has become more urgent than ever because of the sharp increase in cyber threats that are capable of grounding national facilities and other critical economic systems. The capability of criminal state and non-state actors to infiltrate cyberspace and attack private and public businesses have further made it imperative for countries to reassess their cyber security and cyber warfare capability. Consequently, this paper interrogates Nigeria's cyber warfare capability as a tool for enhancing national security.
\end{abstract}

KEYWORDS: Cyber Warfare, Cyberspace, Cyber Infrastructure \& National Security

Received: Mar 14, 2021; Accepted: Apr 04, 2021; Published: Jun 10, 2021; Paper Id.: IJMPERDJUN202144

\section{INTRODUCTION}

The Fourth Industrial Revolution led to a more transformation in the global Information Communication Technology (ICT) that resulted in the emergence of the cyberspace. The rapid development of information technology characterised by the internet has opened new horizons of state governance and created new space to enhance human ability to understand and shape the world (Dilipraj, 2013). The use of this space is fast growing and this cyber domain has become recognised as an environment similar to the sea and air spaces. Cyberspace connotes a global virtual domain characterised by the use of electromagnetic spectrum and computer devices to modify, store and exchange data through networked systems and connected physical infrastructure impacting all aspect of human lives. The emergence of cyberspace has transformed the world into a digitally hyper-connected space with implications on national security. National Security implies a country's ability to make a comfortable internal cum external condition which guarantees socio-economic and economic well-being of the nation and the citizens.

The cyberspace has made the world to become a global village as people in any part of the globe can interact in real-time. Consequently, both private and public organizations are continuously evolving and migrating their operations and services online. Similarly, modern defence systems and industrial production facilities are becoming increasingly connected to computer networks for their control and security. However, there exist people, groups, external intelligence agencies and state facilitated actors and non-state actors that have used the benefit of the cyberspace to carry out nefarious activities that could cause damage to others unaware and unprepared or equipped to deal with such untoward activities. These activities impede the capability of weak states to effectively defend their cyberspace in any case of cyber warfare. 
Consequently, a number of states, developed and developing, invest in the defence of their cyberspace. For instance, In Japan, the cyberspace is used in all activities of government such as policy making, operations, personnel affairs, public relations, research and development, medical and travel agencies among others (Underwood 2002). Japan has a population of 126.3 million with an internet penetration of 93.0 per cent internet users (Kemp 2021). The cyberspace in Japan has become an essential infrastructure that aided numerous operations across the entire domains of land, air, sea and space. As argued by Gady and Koshino (2020), Japan is increasingly building its cyber warfare capabilities through increase in human and material resources. By March 2021, the Japan Self-Defense Forces' (JSDF) Cyber Defence Group (CDG), increased its staff strength from 220 to 290 and also doubled its spending from JP¥11 billion budgeted in 2018 to JP¥25.6bn in 2019 (Gady \& Koshino, 2020). These reformations were preceded by the adoption of the Defence Strategy which paid significant attention to cybersecurity concerns in Japan. The attention by the 2018 defence strategy is reflected in the detailed provisions made in the area of coordinating cyber defence issues. For instance, there are cyber defence units in all the branches of the JSDF, a clear mandate for the protection of cyber infrastructure in all the military arms coordinated by the CDG and the proper assignment of cyber responsibilities divided between internal and external threats to Japan's cyberspace (Onodera 2019; Gady \& Koshino, 2020).

Similarly, in South Africa, the banking industry experienced 61 per cent increase in cyber related attacks between 2016 and 2017 with negative consequences on the performance of that sector (Sutherland, 2017). In 2016, the Post Bank of South Africa lost 4.2 billion Rands to cyber criminals who hacked its computer network (Sutherland, 2017). The South African cyber warfare Barometer of 2016-2017 showed South African economy lost up to 26 billion Rands to cyber attacksduring these years (Sutherland, 2017). To address these issues, the Government enacted a cyber security strategy with a legal framework to prosecute cyber offences in 2015 . While the impact of the SA cyber security strategy is awaited, the Economic Community of Africa estimates that SA still looses about \$573 million yearly from CW (Sutherland, 2017).

\section{CONCEPTUAL CLARIFICATIONS}

\section{Cyber Warfare}

There is no widely accepted definition of cyber warfare. However, a synthesis of the definitions of cyber warfare will be used in this paper. According to Janczewski and Colarik (2008), cyber warfare refers to the various aspects of defending and attacking information and computer networks, as well as denying an adversary's ability to do the same, or even dominating the information environment on the battlefield. This definition presents cyber attacks as conventional warfare. Whereas in life situations, combatants in a cyber attack are amorphous. In most cases, it is difficult to determine the origin and nature of the attack and in assessing the damage incurred. For Clarke and Knake (2014), cyber warfare is an action by a nation-state to penetrate another state's computers or networks to cause damage or disruption. This definition is weakened by its assumption that cyber attacks are limited to state actors alone. In contradistinction, empirical evidence revealed that most attacks emanate from non-state actors such as terrorist groups, pressure groups, among others. Clarke and Knake (2014) attempt to liken cyber warfare to the conventional idea of warfare where nations conduct war using tanks, airplanes, aircraft carriers, among others. This is not the case with cyberspace, because it is warfare evolved with the enemy hiding in the "digital jungle," making it even more difficult to identify. Besides, cyber warfare cannot be limited by boundaries and sovereign territories.

\section{National Security}


Security refers to the feeling of being free from harm or threats. This feeling may occur in the individual or in a group (Udegbunam 2017). Wolfer (1962, p.159) opines that "security, in any objective sense, measures the absence of threats to acquired values, in a subjective sense, the absence of fear that such values will be attacked. The concept of national security has continued to attract the attention of scholars and analysts such that it is difficult to identify a single universally accepted definition. Rooted in the term, security, itself a contested concept, national security discourses have continued to be expanded from the traditional conception of security with the state as the referent object (the protection of the state and its military) to include societal security, which focuses on the people as a critical element of a modern state. It is within this broad understanding that Jordan and Taylor (1981) conceptualise national security to include the security of national values in different sectors of the society-political, economic, and social values. This is in contrast to those scholars such as Lippmann (1943) who prefer to see national security as dealing with state capability to pursue its legitimate national interest with or without resorting to war. This perception of national security indeed captures the ability of a nation to secure its wide interests using whatever means. The definition thus supports the traditionalist perception of security with its reference to the state and its interests.

However, with the wide acceptability of Buzan, Weaver and Wilde, (1998), many scholars tend to view national security beyond state interests to include the interest of the people. For instance, Nwolise (2009) would argue in favour of fifteen dimensions of security, one of which he referred to as technological security. These scholars that share a broad view of security create a justification for the interrogation of cyber defence as an emerging aspect of national security. Thus we conceptualise national security following the broad view of security. National security is therefore the protection of national values and assets of interests, groups and persons under the sovereignty of any nation.

\section{THEORETICAL FRAMEWORK}

A couple of theories could be used in this study. They include Game Theory Structural-Functional Theory, and Securitization Theory (ST). The SST is propounded by Barry Buzan and expanded by Ole Weaver and the Copenhagen School (Buzan, 1991). The major assumption is that there are five aspects of security-military, political, economic, societal, and ecological security (Weaver, Buzan, Kelstrup, \& Lamaitre, 1993). Securitization is the umbrella term for efforts to cope with modern security threats to society itself. The concept is justifying adequate state attention to non-military threats within the society. The ST is seen as a framework that borders on what the state considers security threats. It is so encompassing that it is seen as focusing on society - societal security (Buzan, Weaver \& Wilde, 1998).

Criticism of ST has come from the defenders of the state-centric perspective who argue that the state remains the primary object of security from which other sources may flow. Scholars such as Ejdus (2009) and Huysmans (1998) have consistently criticized ST for its widening of the concept of security to the ridiculous point of including everything as an object of security in the guise of securitization or societal security. Notwithstanding these criticisms, ST has become widely accepted within the security and strategic studies as well as non-military actors. Consequently, the ST is considered relevant to this study. Cyberwarfare represents a security threat to society and by implication to the state. Thus, the ST provides the basis for the interrogation and analysis of cyber warfare into mainstream military warfare and national security. It draws attention to the security threat nature of poor administration of cyberspace and the need for the state to see cyberspace as a security concern and the need to consider cyber threats as an element of primary security threat so that state authority can pay equal attention to its management.

\section{OVERVIEW OF CYBER WARFARE AND NATIONAL SECURITY IN NIGERIA}


Accounting for Nigeria's cyber security and warfare responses should perhaps be traced to the era of facsimile digital communication of the early 1980s (Ogunsola \& Aboyade 2005). Even then digital communications were exposed to criminal abuse by non-state actors who used manipulated telephone lines and used them to send fraudulent messages. These were the first set of scam letters intended to defraud their targets within and outside Nigeria (Ogunsola \& Aboyade 2005). The state response to these sorts of criminal activities was the criminalisation of such acts under Section 419 of the Nigerian Penal Code which made provisions against advance fee fraud(Gwom, Dashe, \& Otor 2016).

By 2000, the Federal Government of Nigeria (FGN) liberalized the telecommunication sector, thus, simultaneously increasing Internet penetration in Nigeria to about 50.0 percent of the population in January 2021 (Kemp, 2021). This also led to increase in cyber criminal activities. As noted by Chawki (2009), Nigerian cyber criminals have defrauded more than 50,000 people from within and outside the nation, resulting in the loss ofover $\$ 5$ billion in a decade. Consequently, Nigerians were vilified all over the world as criminals, losing business transactions opportunities that had negative effects on the economy, external relations and national security of Nigeria.

To contain the increasing cases of cybercrimes, the Nigerian government established the Nigerian Cybercrime Working Group (NCWG) in 2014 and saddled it with the task of framing appropriate legal institutional guidelines for the security of cyber infrastructure in Nigeria (Awhefeada1 \& Ohwomeregwa 2020). The Committee was also to note Nigeria's international obligations as documented in the treaties it entered into while drafting the legal framework for cyber defence and security. The effort of the Committee led to the enactment of an Act against cybercrimes in June 2015 (Awhefeada1 \& Ohwomeregwa 2020). The act is referred to as the Cyber Crimes (Prohibition, Prevention, etc) Act, 2015, entrusted the ONSA with the coordination and enforcement of cybercrimes in Nigeria (Cyber Crime Act, 2015). The legal framework which is the Act is comprehensive and adequate for prosecuting cyber attackers in Nigeria. However, the effective prevention of cyber threats requires an adequate institutional framework to contain attacks on Nigerian cyberspace.

The abuse of Nigerian cyberspace is informed by a number of complex reasons, such as economic and political motives due to porous and unmanned cyberspace orchestrated by poor cyberspace infrastructure. Conducting cyberwarfare requires a country to provide adequate manpower and infrastructure. One of the main tasks of the Computer Emergency Response Team (CERT) at ONSA is to deploy specialized skills and infrastructure in curbing cyber threats. However, the level of manpower and infrastructure needed is still being developed. Hence adequate manpower and infrastructure development are required to conduct cyber warfare.

\section{CONTENDING ISSUES IN CYBER WARFARE AND NATIONAL SECURITY IN NIGERIA}

\section{Nature of Cyber Attacks in Nigeria}

The Nigerian banking industry is the most vulnerable to cyberattacks. Isacenkova, Thonnard, Costin, Francillon, and Balzoratti, (2014), noted that the attackers are usually fraudsters who often harvest addresses and send messages to them. He confirmed that all Nigerian banks encounter fraudsters daily. This underscores the high level of susceptibility in the Nigerian business environment. Economic reasons underlie most of the attacks in Nigerian cyberspace with the banks understandably being the most targeted. Such attacks take the form of compromising online business facilities and sites as well as Automated Teller Machines (ATM)As further enunciated by Monsuro (2017), the websites of government economic agencies such as the Central Bank of Nigeria (CBN) and the Nigerian Stock Exchange were at different times targeted by economic hackers seeking to compromises electronic payment systems because of the security of the weak security of Nigeria's cyberspace. 
There have also been attacks motivated by political reasons. For instance, Monsuro (2017) reported that a group referred to as Naija Cyber Hacktivists who have attacked government websites in protest against political decisions. The expansion of broadband accessibility and the inter-connectivity by Galaxy Backbone, in addition to the cashless policy of the CBN further attracts the attention of criminal elements to Nigeria's cyberspace. Consequently, this poses a threat to economic values which is an aspect of national security in Nigeria. The enormity of cyber criminal activities in Nigerian cyberspace has earned it $3^{\text {rd }}$ position in the global ranking in the prevalence of cyber crime by the Internet Crime Complaint Centre (ICCC) (ICCC 2017).

\section{Institutional Framework}

Institutional framework specifies the regulatory agencies in the performance of their statutory functions in the use of cyberspace for enhanced national security. The lead agency for the coordination of the use of cyberspace is ONSA as stipulated in the National Cybersecurity Policy and Strategy 2014. To checkmate fraudulent activities within Nigerian cyberspace, the FGN established the NCWG in March 2004 to coordinate key law enforcement, security, intelligence, and ICT agencies in a multi-agency approach to fighting crime. The Committee, chaired by the National Security Adviser (NSA) is an inter-agency body made up of all critical law enforcement, security, intelligence agencies of government, and major private organizations in the ICT sector. The inadequacy of these institutional frameworks led to the creation of the DSA in 2016 to manage and coordinate all space concerns of the nation in collaboration with other security agencies in cyber warfare for enhanced national security.

\section{Defence Cyberspace Infrastructure}

Cyberspace infrastructure entails the facilities that consist of computer networks, hardware, and software that ensure effective use of cyberspace for enhanced national security. The cyberspace infrastructure covers the hosts, intermediate switching elements, hubs, bridges, optical fibres, routers, gateways, and mast stations. Also, the software part covers all application programming and network protocols that synchronize and coordinate the sharing and exchange of data among the networks. The human ware includes the users that create, exchange, and use information. In Nigeria, cyberspace infrastructures are not in place which made the various service providers embark on constructing these facilities nationwide. Each network laid its fibre optic backbone and mast stations, powered by generators with attendant costs. Furthermore, the cyberspace infrastructures to serve the country's cashless and online policies were lacking, making government rely on private service providers.

The Nigeria Interbank Settlement System (NIBSS) which provides infrastructure for fund transfer and Automated Teller Machine (ATM) to facilitate a cashless transaction is jointly funded by the government and the private banks (Cyber Crime Act, 2015). In 2011, the FGN utilized the gateways owned by private service providers in cyberspace to detect the increase in cybertheft by over 30 percent thereby necessitating a quick response of the EFCC (Lazarus \& Okolorie, 2019). Before 2001, Nigerian Telecommunication (NITEL) was Nigeria's national telecommunications trunk carrier and provided a national gateway through which all internet, call traffic, and other virtual domain transactions within and outside the country must pass through. This facilitated easy monitoring, control, and access to Nigeria's cyberspace. Cyber-crimes that target and attack national critical information infrastructure pose a serious threat to national security. The Cyberspace infrastructure is, therefore, a critical issue in cyber warfare for enhanced national security.

\section{Human Capital Development}


Human capacity refers to the process of systematically training individuals to bring out their potentials for the benefit of the individual, organization, or society as a whole. This is measured in the ability of the individual to discharge his or her task efficiently. The ability to carry out the task depends on the level of training, education, and expertise. Technical capacity is synonymous with the ability needed to tackle any emerging challenges in all facets of human endeavour (Muller, 2015). The use of cyberspace is one of the new emerging challenges in human society that requires human knowledge, expertise, and training.

In Nigeria, several agencies are involved in cyberspace monitoring and evaluation. These include the Office of the National Security Adviser (ONSA), Economic and Financial Crime Commission (EFCC), the Nigerian Police Force (NPF), National Intelligence Agency (NIA), among others. The ONSA is the lead agency in cyberspace administration and coordinating agency on national security in the country. The ONSA has about 22 personnel trained on cybersecurity and cybercrime detection while the EFCC trained 50 forensic cybersecurity experts between 2012 and 2016 (Lazarus \& Okolorie, 2019). The Galaxy Backbone, a company specialized in ICT and cyberspace-related issues have trained about 400 staff of Ministries, Departments and Agencies (MDAs) who engage in ICT and cyber-related businesses. These numbers of personnel are grossly inadequate considering the coverage of over $350 \mathrm{~km}$ and 150 MDAs and the range of the use of cyberspace by other service providers.

\section{CHALLENGES FACING CYBER WARFARE AND NATIONAL SECURITY IN NIGERIA} Lack of Cyber Offensive Capability

Nigerian cyber warfare capability is low due to the inability of the military to articulate, prepare and build its cyber defence infrastructure. Understandably, traditional military training in developing states, such as Nigeria, had little or no cyber security contents. Faced my myriads of external and internal security threats that include terrorism from Boko Haram and herdsmen in many parts of the country, the military's resources have become so depleted that the enthusiasm to lunch into a relatively new area of combating cyber threats have become a serious challenge. This has resulted in low response and passivity to the issues of offensive cyber warfare capability.

\section{Weak Institutional Synergy}

The weak institutional synergy among stakeholders is a challenge militating against institutional framework in the use of cyberspace for enhanced national security in Nigeria. There are different stakeholders involved in the management of cyberspace in Nigeria. These stakeholders include DSA, Defence Headquarters (DHQ), DIA, NPF, EFCC, ONSA amongst others. Rather than a synergetic collaboration, each of the stakeholders operates independently, creating a gap in cyber warfare for enhanced national security. The world today accounts for over 3 billion internet users of which Nigeria contributes over 100 million active subscribers with 33 million active accounts in social media (Kemp 2021). Unless a comprehensive institutional framework is formulated for the coordination of all stakeholders in the use of cyberspace by way of sharing information among the stakeholders, cybercrimes will continue to thrive in the country thereby negatively affecting national security.

It is in the realization of this that Section 5.2.2 of the National Cyber Security Policy and Strategy 2014 spelt out the need for unified coordination of national cybersecurity policies and strategies in Nigeria by the ONSA (Cyber Security Policy). The lack of synergy among stakeholders is evident in the inability of the Sectoral CERT to link one another in realtime operation. For instance, the ONSA as the lead agency is supposed to domicile the Nigerian CERT (ngCERT) and 
coordinate all other Sectoral CERTs could not do so due to lack of synergy. The ONSA often gets its information by making voice contact with other sectoral CERTs. This process delays response time in emergencies and could also lead to the divulging of vital intelligence to unauthorized persons hence negatively affecting national security. With the creation of DSA which is now charged with the facilitation and implementation of the Defence and Security aspect of the National Space Policy, this may have to be properly managed. Thus, weak institutional synergy among stakeholders is a hindrance to cyber warfare for enhanced national security in Nigeria.

\section{Lack of National Cyberspace Gateway}

Lack of national cyberspace gateway is a challenge to cyberspace infrastructure which is a hindrance to effective cyber warfare for enhanced national security. A gateway is a network node that provides high-level secured network system communication. The deregulation of the telecoms sector and eventual sale of Nigerian Telecommunication (NITEL), gave rise to the decentralization of gateways, where each Service Providers operated its gateway. Consequently, there was no national gateway that serves as a central traffic hub for data and voice communications, leaving cyberspace prone to threats by state and non-state actors. For instance, in 2015, the Nigeria Deposit Insurance Corporation reported 12,279 fraud cases within the banking industry (NDIC, 2015). The loss to various financial crimes in the banking sector was $₹ 2.37$ billion in 2017 and 15 billion in 2018 respectively (Ogbonnaya, 2020). Nigeria loses 127 billion every year to cyber-crimes (Richards, 2017). This is attributed to the lack of a national cyberspace gateway in the country thereby undermining national security.

\section{Inadequate Technical Expertise}

Inadequate technical expertise is a challenge militating against human capacity in the use of cyberspace in Nigeria for enhanced national security. Cyberwarfare is technologically based and therefore needs persons with the technical know-how of cyberspace. Lawal (2017) opined that the dearth of personnel with technical knowledge in cyberspace is a major challenge to ONSA and other stakeholders in dealing with the application and use of cyberspace in Nigeria. He further revealed that "the country from 2017 to 2020 needs about 2000 to 3000 personnel efficient in technical and general knowledge in the use of cyberspace to counter the emerging challenges in cyberspace. Lawal (2017) also noted that the NCC is presently challenged in discharging its duties in the use of cyberspace due to inadequate technical expertise. He further revealed that the Commission has only 5 personnel trained in cyberspace technology as against 50 personnel projected. The lack of technical expertise undermines cyber warfare for enhanced national security.

Cyberspace encompasses other subsets such as cybercrime, cybersecurity, and cyber commerce among others. All of them require high technical knowledge. To compete favorably and effectively utilize cyberspace, Nigeria needs to counter the negative effects of cyberspace while maximizing the opportunities it avails. Due to inadequate technical expertise in cyberspace in the country as revealed by NCC, Nigeria lost about USD 2.1 million in the banking sector and USD 2.8 million on ICT importation in 2016 (CBN Annual Report, 2016). This negatively affects the GDP thereby impinging on national security. Therefore, inadequate technical expertise is a challenge militating against cyber warfare for enhanced national security.

\section{Way Forward}

Linkage of Sectorial Cert to National Coordination Centre 
The linkage of the Sectorial CERT to the National Coordination Centre will address the challenge of weak institutional synergy in cyber warfare for enhanced national security in Nigeria. The objective is to ensure the unified coordination of cyber warfare. The ONSA is to coordinate the linkage of the Sectorial CERT to the NCII and to be domiciled in ONSA with DSA playing a central role. The National Coordination Centre could be manned by a staff of ONSA with desk officers from DSA, NIA, CBN, NCC, FMF, FMJ, DSS, NPF, ICPC, and DHQ. This Centre could also serve as a data collation base and to be linked to the various agencies in the network. The ONSA could forward the proposal for the linkage of the Sectorial CERT to National Coordinating Centre to the Presidency.

\section{Development of Cyberspace Protection Infrastructure}

The development of cyberspace protection infrastructure would mitigate the challenge of the lack of a national cyberspace gateway for the use of cyberspace for enhanced national security in Nigeria. The objective of this strategy is to provide a high-level secured network communication system for the protection of cyberspace infrastructure in the country. The DSA under the supervision of the ONSA in conjunction with the Nigerian Communication Commission (NCC) could set up a technical committee to work out modalities for developing cyberspace protection to secure the nation's critical cyberspace infrastructure. This would ensure secured cyberspace and reduce cyber-threats thereby enhancing national security. The FGN through ONSA could appropriate funds from existing resources.

\section{Development of Cyber Offensive Capability}

This would require key agencies and state institutions such as the military, the National Information Technology Development Agency (NITDA), NCC and Galaxy Backbone to partner with Defence Space Administration (DSA) to evolve national cybersecurity doctrine that would articulate Nigeria's offensive cyber warfare capabilities. This institutional approach is most required for the progressive building up of cyber power for a possible future cyber offensive. Notable repentant hackers could be granted amnesty, trained and drawn into participating in building cyber warfare resilience for Nigeria. This approach has been explored in other areas of national security such as integrating repentant Boko Haram terrorist members into the military or using repentance Niger Delta militants in managing pipeline security.

\section{Capacity Building for Cyberspace Personnel}

The capacity building for cyberspace personnel would address the challenge of inadequate technical expertise. The objective is to train persons with technical know-how to operate in cyberspace for improved use of cyberspace in warfare for enhanced national security. The training of persons especially those in security agencies in cybersecurity and prevention would improve cyber warfare in Nigeria. The personnel could be trained in technical equipment, tools, ICT, intelligence, and information gathering. They could also be trained as cyber warriors for offensive and counter-attack squad. The FGN could direct the Defence Security School (DSS) of the DSA to take off and begin training personnel from EFCC, AFN, the NPF, Department of State Security (DSS), NIA, and Independent and Corrupt Practices Commission (ICPC) to conduct formal certificated training on cyberspace security. Each of the agencies could sponsor the training from their resources.

\section{Enforcement of the Cybercrimes Act 2015}

The enforcement of the Cybercrimes Act 2015 would address the challenge of weak implementation of the Act. The objective is to ensure the implementation of the provisions of the Act. To achieve this, the FGN through ONSA could constitute an 
Implementation Task Force composed of representatives of ONSA, DSA, NIA, CBN, NCC, Federal Ministry of Finance (FMF), Federal Ministry of Justice (FMJ), DSS, NPF, ICPC, and DHQ to enforce the implementation of the provisions of the Act.

\section{CONCLUSIONS}

The centrality of cyberspace in contemporary global affairs requires that modern states pay serious attention to cyber power and capability. Nigeria's cyber infrastructures are only emerging and most of them vulnerable to cyber-attacks. Future conflicts will most likely be fought in the cyberspace. Consequently, the protection of national security would require conscious investment into cyber resilience and cyber defence infrastructure. As a result, the challenges facing Nigeria's cyberspace identified in this paper such as lack of cyber offensive capability, weak institutional synergy, lack of national cyberspace gateway, and inadequate technical expertise, would need to be carefully managed to improve Nigeria's cybersecurity.

\section{REFERENCES}

1. Awhefeadal, U.V.and Ohwomeregwa, O. B. (2020)Appraising the Laws Governing the Control of Cybercrime in Nigeria Journal of Law and Criminal Justice June 2020, Vol. 8, No. 1, pp. 30-49

2. Bishnu Pada Roy, “'Crossing Over' the (Blurred) Lines among Reality, Virtuality, and Theatricality: A Cyberpsychoanalytical Study of the Nether by Jennifer Haley",International Journal of English and Literature (IJEL),Vol. 7, Issue 5, pp, 47-56

3. Buzan, B. (1991). Peoples, states and fear. Harvester: Wheatsheaf.

4. Dr. Bhargavi D Hemmige, "Gutenberg's Bible to Zuckerberg's Facebook - The Changing Dynamics of Sharing Information", International Journal of Communication and Media Studies (IJCMS), Vol. 9, Issue 3,pp, 187-194

5. Buzan, B., Waever, O. and De Wilde, J. (1998) Security: a New Framework forAnalysis. Boulder, Colorado: Lynne Rienner.

6. Rafidha Rehiman KA \& Lakshmi KS, "A Secret Sharing Scheme and National Security Enhancement through Natural Language Processing",International Journal of Computer Science and Engineering (IJCSE),Vol. 2, Issue 3,pp, 47-52

7. Central Bank of Nigeria (2016) CBN Annual Report 2016. Available at www.cbn.gov.ng

8. Chawki, M. (2009) Nigeria tackles advance fee fraud. Journal of Information, Law and Technology, vol. 2009, no. 1, Gale Academic OneFile.

9. Yuvraj Singh, "Conceptual Study on Network Security and Its Types",International Journal of General Engineering and Technology (IJGET),Vol. 6, Issue 5, pp; 37-42

10. Clarke, R. A., and Knake, R. K. (2014). Cyber war. Old Saybrook: Tantor Media, Incorporated.

11. Ejdus, F. (2009) Dangerous Liaisons: Securitization Theory And Schmittian Legacy, Western Balkans Security Observer English Edition, (13), pp. 9-16

12. Federal Republic of Nigeria (2015) The Cybercrimes (Prohibition, Prevention, Etc) Act,2015https://www.cert.gov.ng/ngcert/resources/CyberCrime_Prohibition_Prevention_etc_Act_2015.pdf.

13. Gady, S. and Koshino, Y. (2020) Japan and cyber capabilities: how much is enough? https://www.iiss.org/blogs/militarybalance/2020/08/japan-cyber-capabilities,

14. Gwom, G.S., Dashe, D.N., and Otor, E.I. (2016) A Focus on Advanced Fee Fraud in Nigeria: Nature, Prevalence and the Urgent 
Need for Enforcement of Relevant Laws, Public and International Law Journal, Faculty of Law, Nasarawa State University, Accessed fromSSRN: https://ssrn.com/abstract=3421734 or http://dx.doi.org/10.2139/ssrn.3421734

15. Huysmans, J. (1998) The Question of Limit: Desecuritization and the Aesthetics of Horror in Political Realism.Millenium: Journal of International Studies, 27 (3), 569-589

16. Insurance Corporation(2015) NDIC releases 2015 annual report. Accessed from https://ndic.gov.ng/ndic-releases-2015annual-report/.

17. Internet Crime Complaint Centre (2017). 2017 Internet Crime Report. Accessed fromhttps://www.ic3.gov/Media/PDF/AnnualReport/2017_IC3Report.pdf

18. Isacenkova, J., Thonnard, O., Costin, A., Francillon, A., Balzoratti, D (2014) Inside the scam jungle: a closer look at 419 scam email operations. EURASIP J. on Info. Security, 4

19. Jordan, A.A.and Taylor, W.J. (1981) American National Security: Policy and Process, Johns Hopkins University Press

20. Kemp, S. (2021) Digital 2021: Nigeria. Accessed from https://datareportal.com/reports/digital-2021-Nigeria.

21. Kemp, S. (2021) Digital Japan https://datareportal.com/reports/the-unique-nuances-of-digital-in-japan.

22. Lawal, M. S. (2017) Cybersecurity policy and strategy in Nigeria: An Overview, A Paper Presented at the National Defence College, Abuja On 8 November 2017.

23. Lazarus, S., and Okolorie, G. U. (2019). The bifurcation of the Nigerian cybercriminals: Narratives of the Economic and Financial Crimes Commission (EFCC) agents. Telematics and Informatics, 40, 14-26.

24. Lippmann, W. (1943) U.S. Foreign Policy: Shield of the Republic. Boston: Little, Brown,

25. Monsuro, F (2017). Nigeria: Cyber Security - A Matter of Concern for Nigerian Boards, MONDAQ, 3 May 17. $<$ http://www.mondaq.com/

26. nigeria/x/591058/security/cyber-security-a-matter-of-concern-for-nigerian-boards/>,accessed 8 Nov 17

27. Muller, L.P. (2015) Cyber Security Capacity Building in Developing Countries: Challenge and Opportunities. Oslo; Norwegian Institute for International Affairs Nigeria Deposit

28. Nwolise, O.B.C. (2009). Peace and security. In. Praxis of political concepts \& clichés in Nigeria's fourth republic-essays in honour of Dr. Muazu Babangida Aliyu. Ibadan: Bookcraft. Pp. 245-278

29. Ogbonnaya, M. (2020) Cyber crime in Nigeria demands public-private Accessed from https://issafrica.org/isstoday/cybercrime-in-nigeria-demands-public-private-action.

30. Ogunsola, L.A. and Aboyade, W.A. (2005)Information and Communication Technology in Nigeria: Revolution or Evolution, Journal of Social Sciences, 11(1)7-14

31. Onodera, I. (2019) Japan's New National Security Policy and Defense Strategy in a New Era, Asia-Pacific Review, 26:(2) 3749

32. Richards, O. (2017) 'Nigeria loses N127b yearly to cybercrimes. Accessed from https://guardian.ng/technology/nigeria-losesn127b-yearly-to-cybercrimes /

33. Udegbunam, K. C.W. (2017). Basic concepts and framework models in Peace and Conflict Studies. In A. O. Onu, J. Eze and K.C.W. Udegbunam Social Sciences Perspectives to Peace and Conflict Studies, Vol. 2. Enugu: Grand Heritage Communication

34. Underwood W. (2002) Embracing cyberspace - The Evolution of Japan's Internet Culture. The World \& I;17(6):265-. 
35. Wever, O., Buzan, B., Kelstrup, M., Lemaitre, P. (1993) Identity, Migration and the New Security Agenda in Europe, London: Pinter Publishers Ltd.

36. Waziri, F. M. (2005) Advance Fee Fraud, National Security and the Law, Ibadan. Book builders

37. Wolfers, A. (1962). Discord and collaboration. Baltimore: Johns Hopkins Press. 
